\title{
IMMUNOHISTOCHEMICAL LOCALIZATION OF INDUCIBLE NITRIC OXIDE SYNTHASE IN PLEOMORPHIC ADENOMA OF SALIVARY GLAND: CORRELATION WITH CYCLOOXYGENASE-2 AND TUMOR PROLIFERATIVE ACTIVITY
}

\author{
Hamdy AbdelMotagaly Metwaly*
}

\begin{abstract}
Objectives: to investigate immunohistochemically localization pattern and distribution of inducible Nitric Oxide Synthase (iNOS) in pleomorphic adenoma (PA) of salivary glands and to find a correlation of its expression with Cyclooxygenase-2 (COX-2) and tumor proliferative activity.

Material and Methods: 18 cases of PA were subjected to immunohistochemical staining for iNOS, COX-2 and proliferative cell nuclear antigen (PCNA) using streptavidin-peroxidase technique. 10 samples of normal salivary glands tissues (NSG) were used as a control. COX-2, iNOS and PCNA expression were statistically compared.
\end{abstract}

Results: in PA, expression of iNOS was increased as that of COX-2 when compared with the control. The expression intensity and pattern of distribution of studied proteins were different within the tumor tissue. The strong expression was localized mainly at the tumor periphery while the center of tumor showed weak or even negative expression. The PCNA-LI mean percentage was higher in the periphery of the tumors. The low expression scores of iNOS were detected in 4 cases, moderate in 5 cases and high in 7 cases, whereas the expression scores of COX-2 were observed in 5 cases (low), in 9 cases (moderate) and 5 cases (high). The expression scores of iNOs and COX-2 were significantly correlated $(P \leq 0.05)$. Significant correlation of expression scores of COX-2 and iNOS with PCNA-LI $(P \leq 0.01)$ were found.

Conclusion: this study revealed that COX-2 and iNOS expression was increased significantly in PA. Their pattern of expression was more in the periphery of the lesion than the center. The labelling index of PCNA was higher in the periphery of the lesion indicating that the tumorous and proliferative activity of PA is more at tumor tissues near the margins suggesting that the aggressiveness of $\mathrm{PA}$ is at the tumor peripheries.

KEY WORDS: Pleomorphic adenoma, iNOS, COX-2, PCNA, Immunohistochemistry

\footnotetext{
* Assistant Professor, Department of Oral Pathology, Faculty of Dentistry, Tanta University
} 


\section{INTRODUCTION}

Several molecules including COX-2 and iNOS have been identified to have essential roles in suppression of apoptosis, proliferation, angiogenesis, invasion, and metastasis ${ }^{(1,2)}$. In response to pro-inflammatory agents, iNOS continuously produces sustainable concentrations of nitric oxide (NO) ${ }^{(1)}$ which consider as one of the major mediator of chronic inflammation ${ }^{(1)}$. It was reported that $\mathrm{NO}$ has a role in tumorigenesis and may modulate several cellular processes such as cell proliferation, survival and migration. In addition, it can modulate angiogenesis, drug resistance, DNA modifications and inactivation of DNA repair enzymes ${ }^{(1,3)}$. COX is an enzyme that have cyclooxygenase and peroxidase activities and it constitute two isoforms of enzyme ${ }^{(2)}$. COX-1 which expressed constitutively in most tissues producing prostaglandins for homeostatic functions $(2,4,5)$. Whereas, COX-2 is activated by various stimuli at the sites of inflammation such as growth factors, inflammatory cytokines and oncogenes ${ }^{(2)}$.

Upregulation of iNOS and COX-2 have been found in various human tumors ${ }^{(6-12)}$. iNOS was upregulated in hepatic carcinoma, thyroid carcinoma, squamous cell carcinoma and ameloblastoma ${ }^{(3,6,7,9,11,13)}$ while upregulation of COX-2 was reported in colonic carcinoma (14), gastric carcinoma ${ }^{(16)}$, prostate carcinoma ${ }^{(17)}$, high grade gliomas ${ }^{(18)}$, malignant melanoma ${ }^{(19)}$ and in thyroid carcinomas ${ }^{(20)}$.

Upregulation of COX-2 in salivary gland tumors has been demonstrated in the previous reports ${ }^{(21-22)}$. In our previous studies on salivary gland tumors, we verified that expression of COX-2 was significantly upregulated in mucoepidermoid carcinomas and Adenoid cystic carcinoma when compared with PA (23). We also reported that upregulated expression of both iNOS and COX-2 might have a role in malignancy in mucoepidermoid carcinomas of salivary gland ${ }^{(24)}$.
PCNA, a proliferation marker previously used in several neoplasms correlated to clinical outcomes ${ }^{(25)}$. Also, PCNA expression level have been increased in biologically aggressive neoplasms including salivary gland tumors ${ }^{(26,27)}$.

Although expression of COX-2, iNOS and PCNA have been studied in benign and malignant salivary gland tumors. The present study focused on their immunolocalization and distribution pattern within the PA tissues and the correlation between them.

\section{MATERIAL AND METHODS}

Eighteen cases of PA of salivary glands diagnosed based on the clinical and histopathological examination were retrieved from archives of Oral Pathology Department, Faculty of Dentistry, Tanta University. All samples were excised from intraoral minor salivary gland tumors with normal salivary tissue (NSG). The patients' recorded data were retrieved from the archives. Samples of NSG tissues adjacent to the tumor of 10 cases were used as control.

The paraffin blocks of selected cases of PA were cut into sections of $5 \mu \mathrm{m}$ thickness subjected for hematoxylin and eosin (HE) staining. All cases were examined to confirm the diagnosis of PA and the presence of NSG tissues associated.

\section{Immunohistochemistry}

Immunohistochemical technique used in this study was a peroxidase labeled streptavidin-biotin complex. Serial sections of $5 \mu \mathrm{m}$ thickness were obtained from the paraffin blocks of PA cases subjected for immunohistochemical staining as described elsewhere ${ }^{(23,24)}$. The primary antibodies used were a rabbit polyclonal antibody for iNOS (Thermo Fisher Scientific, Fremont, USA), mouse monoclonal antibody for COX-2 (160112; Cayman, USA) and mouse monoclonal antibody for PCNA 
(clone PC10, DakoCytomation, Copenhagen, Den). The primary antibodies were diluted in phosphate-buffered saline (PBS) according to the manufacturer's instructions. The sections associated with the kits were used as positive control. Normal mouse or rabbit IgGs were used replacing the primary antibodies as negative control.

\section{Analysis of the staining}

The positive expression for iNOS and COX2 was appeared as brown cytoplasmic staining, seen by a light microscope. This cytoplasmic staining intensity and distribution were evaluated in all cases by a reported scoring system with little modification ${ }^{(11)}$. Five random fields of sections at power $\mathrm{x} 400$ were examined under light microscope. The staining intensities of iNOS and COX-2 was graded into 4 scores according to the color of the staining from $0-3$ scores as follows 0 ; negative score (no staining), 1 ; weakly positive (light yellow), 2; moderately positive (yellowish brown) and 3; strongly positive (dark brown). The proportion of positive staining cells (percentage) was scored as follows, negative $(0),<10 \%$ positive cells (1), $10 \%-50 \%$ positive cells (2) and $>50 \%$ positive cells (3). The total score was calculated as the result of intensity score multiplied with the score of percentage of positive cells for each specimen. The overall results of 1,2 considered low scores of expression (+). Score 3 and 4 considered moderate scores of expression (++) and score 6 and 9 considered high score of expression (+++) whereas score (-) was negative for iNOS and COX-2.

\section{Analysis of PCNA staining}

The percentage of PCNA immunopositive cells (brown stained nuclei) at the center and periphery of the tumor to total number of cells at $400 \mathrm{x}$ magnification was calculated in five microscopic fields captured with a camera and the mean was determined automatically using MacBiophotonics ImageJ v.1.44e, analysis software.

\section{Statistics}

The data were statistically analyzed using a computer software program SPSS ver. 15.0. The two groups were compared using Student's t-test and Fisher's exact test to get statistically significant differences with $p$ value less than 0.05 . In order to analyze the correlation between markers, a nonparametric Spearman rank-order test was used.

\section{RESULTS}

\section{Patients and Clinical Data}

The detailed clinical data for 18 studied cases of PA are showed in table1. It revealed that the mean age was 35 years ranging from 10 to 65 years. 8 cases in male and 10 cases in female. The mean size of the tumor was $1.94 \mathrm{~cm}$ ranged between 0.5 and $4 \mathrm{~cm}$. The palate was the common site (13 cases) $72.2 \%$, and the maxilla (5 cases) $27.8 \%$. No pain complaint recorded in any case.

TABLE (1) Clinical data of studied cases of PA

\begin{tabular}{cc|cc|ccc}
\hline \multicolumn{2}{c|}{ Site } & \multicolumn{2}{|c|}{ Sex } & \multicolumn{2}{c}{$\begin{array}{c}\text { Mean } \\
\text { size }(\mathbf{c m})\end{array}$} & \multicolumn{2}{c}{$\begin{array}{c}\text { Mean Age } \\
\text { (year) }\end{array}$} \\
\hline Palate & Maxilla & M & F & & M & F \\
\hline 13 & 5 & & & & & \\
$(72.2 \%)$ & $(27.8 \%)$ & 8 & 10 & 1.94 & 48 & 25 \\
\hline
\end{tabular}

\section{iNOS Expression}

No staining was observed in negative control. Positive expression of iNOS was observed as a brown staining in the ductal cells of NSG (Fig1A). In PA, iNOS was expressed in the cytoplasm of tumor cells including ductal cells and myorepithelial cells with various staining intensities ranged from mild to strong expression (Fig1B-D). Myoepithelial cells of myxomatous tissue also showed positive expression for iNOS. In the periphery of the lesion, the expression score was moderate to high 
in comparison to the center of the lesion, which appeared weak staining or even negative. iNOS expression score are shown in table 2 and chart1.

\section{COX-2 Expression}

In the negative controls, no staining was seen. In NSG, the expression of Cox-2 was a cytoplasmic brownish precipitate observed mainly in the duct cells (Fig 2A). In PA, moderate to strong expression of COX-2 was seen in tumor cells of ducts but it was moderate in myoepithelial cells (Fig 2 B-D). The expression distribution pattern was also more at the periphery of PA than in the center of the lesion. COX-2 expression scores are shown in table 2 and chart1.
TABLE (2) Expression scores of iNOS and COX-2 in PA and NSG tissues

\begin{tabular}{|l|c|c|c|c|}
\hline \multirow{2}{*}{ Expression Score } & \multicolumn{2}{|c|}{ iNOS } & \multicolumn{2}{c|}{ COX-2 } \\
\cline { 2 - 5 } & PA & NSG & PA & NSG \\
\hline Negative (-) & 2 & 3 & 0 & 2 \\
\hline Low (+) & 4 & 4 & 5 & 6 \\
\hline Medium (++) & 7 & 3 & 9 & 1 \\
\hline High (+++) & 5 & 0 & 4 & 0 \\
\hline Total & 18 & 10 & 18 & 10 \\
\hline
\end{tabular}

\section{Correlation of iNOS and COX-2 Expression}

The correlation between the expression of both molecules was significantly positive $P$-value $=0.024 \mathrm{P}<0.05($ table 3 , Graph 1$)$.

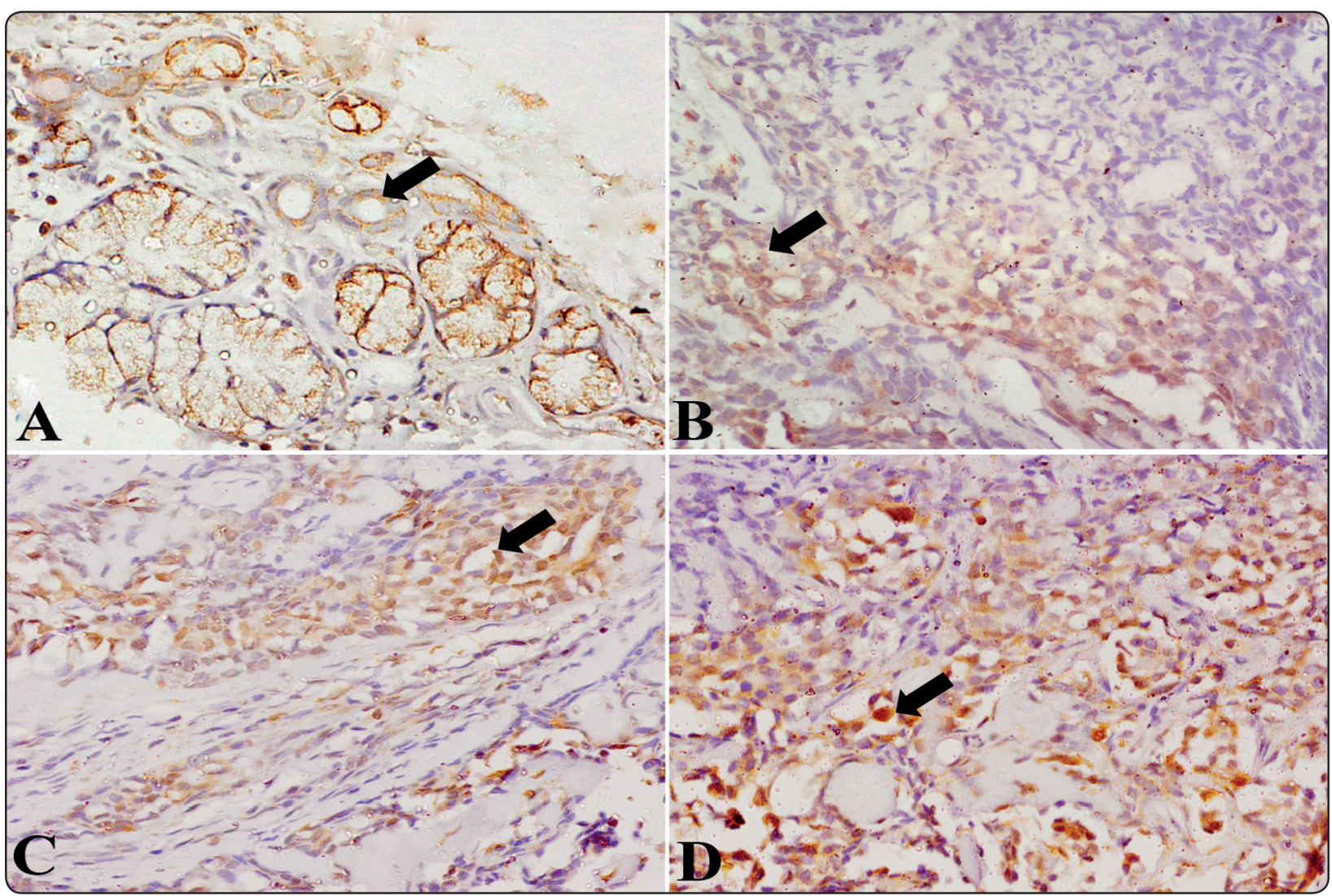

Fig. (1) Immunohistochemical staining of iNOS in PA. A) NSG and B), C), D) PA. Hematoxylen counter stain. In NSG, a cytoplasmic expression of iNOS observed mainly in the duct cells (arrow) (A). Positive cytoplasmic staining of iNOS appeared in tumor cells with various intensity score ranged from low expression in periphery of the lesion (B) to moderate expression $(\mathrm{C})$ and high expression in center of the lesion (arrow) (D). X- 200 


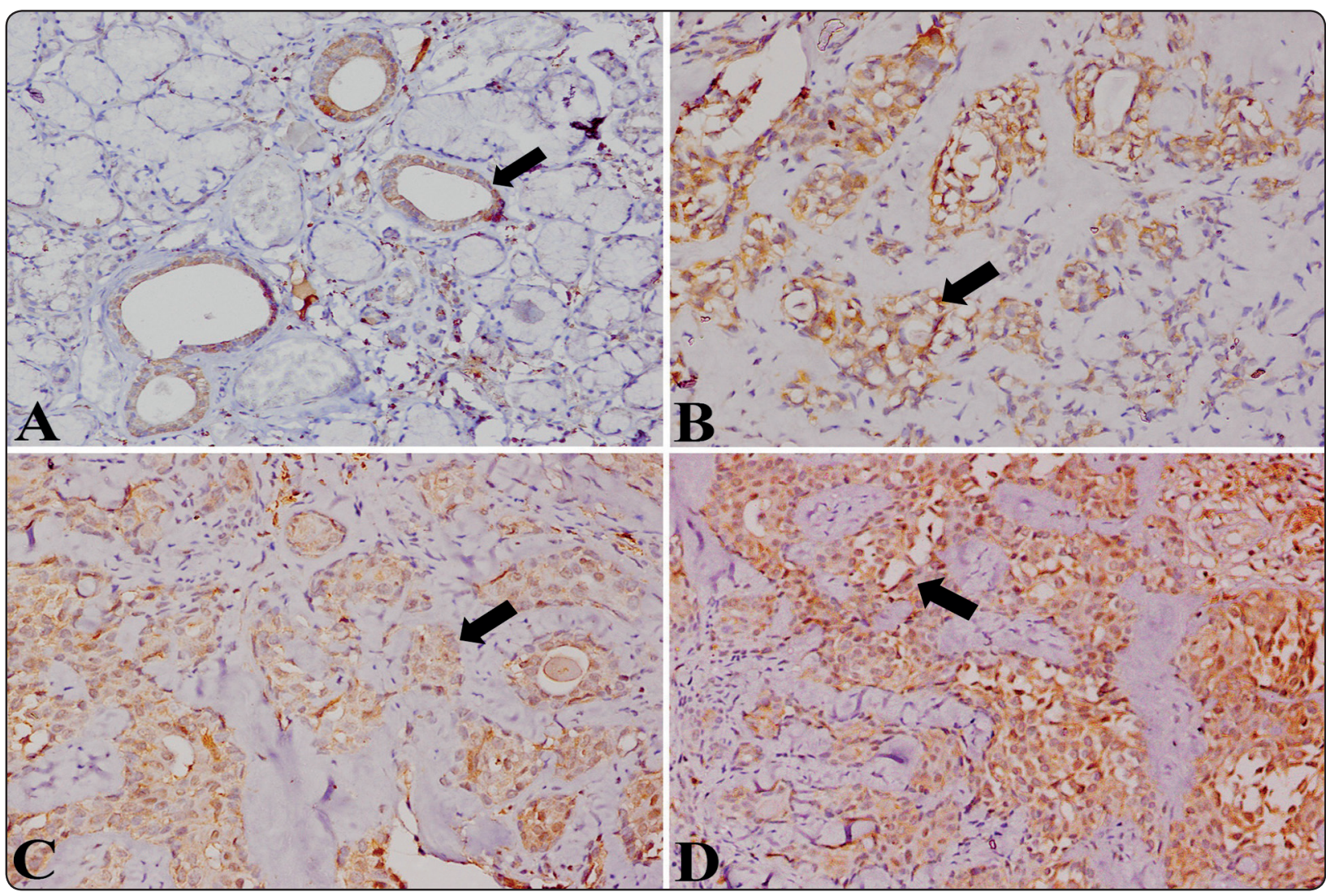

Fig. (2) COX- 2 Immunohistochemical staining in PA. A) NSG and B), C), D) PA. Hematoxylen counter stain. In NSG, the expression of COX-2 was a cytoplasmic brownish precipitate observed mainly in the duct cells (arrow) (A). The expression of COX-2 appeared as cytoplasmic brownish staining of the tumor cells. The expression score ranged from low expression in periphery of the lesion (B) to moderate expression (C) and high expression in center of the lesion (arrows) (D). X- 200.

TABLE (3) Expression scores of iNOS and COX-2 and PCNA-LI \% in PA and NSG tissues

\begin{tabular}{|c|c|c|c|c|c|c|}
\hline \multirow[b]{2}{*}{ Expression Score } & \multirow[b]{2}{*}{ iNOS } & \multirow[b]{2}{*}{ COX-2 } & \multirow[b]{2}{*}{ P-Value } & \multicolumn{2}{|c|}{ PCNA-LI \% } & \multirow[b]{2}{*}{ P-Value } \\
\hline & & & & $\begin{array}{l}\text { Center of the } \\
\text { lesion }\end{array}$ & $\begin{array}{l}\text { Periphery } \\
\text { of the lesion }\end{array}$ & \\
\hline Negative (-) & 2 & 0 & \multirow[t]{4}{*}{$0.05^{*}$} & \multirow[t]{4}{*}{12.3} & \multirow[t]{4}{*}{15.4} & \multirow[t]{4}{*}{$0.01 * *$} \\
\hline Low (+) & 4 & 5 & & & & \\
\hline Medium (++) & 7 & 9 & & & & \\
\hline High $(+++)$ & 5 & 4 & & & & \\
\hline
\end{tabular}

* Significant at 0.05 levels $(P \leq 0.05)$

** Significant at 0.01 levels $(P \leq 0.01)$ 


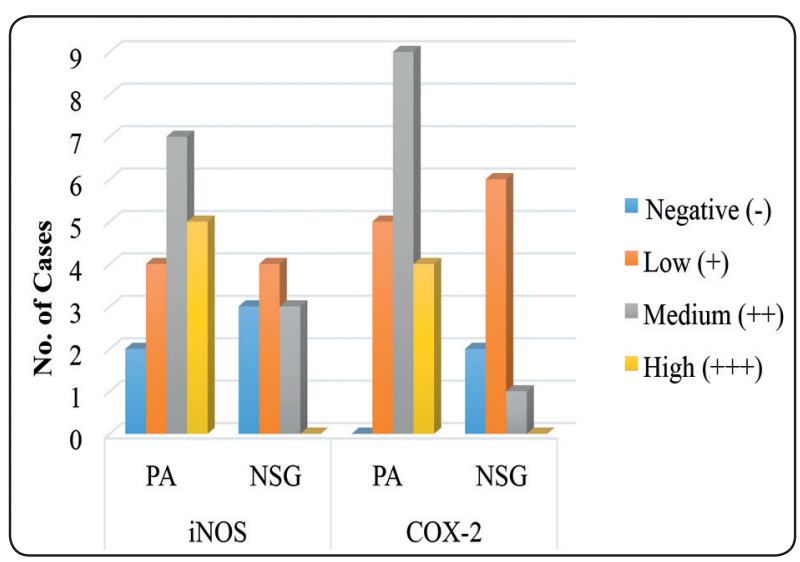

Chart 1: Bar chart showing the expression scores of iNOS and COX-2 in PA and NSG tissues

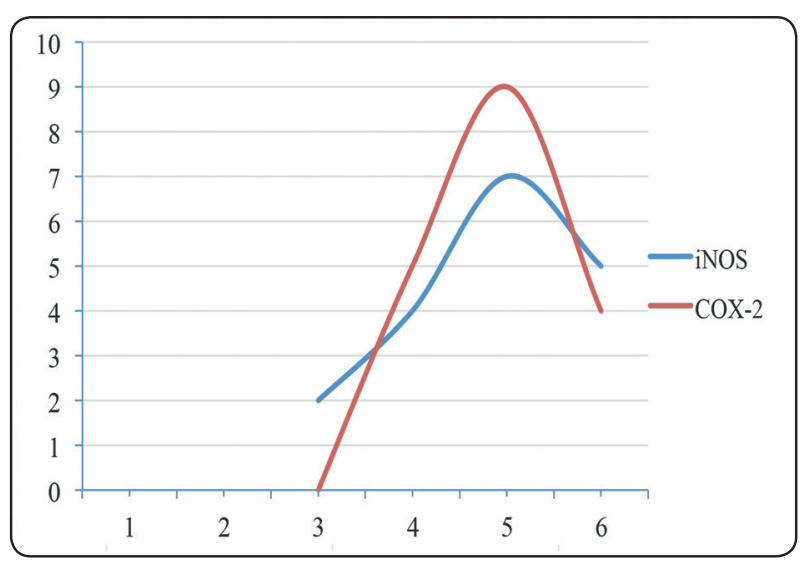

Graph 2: showing the correlation between Cox-2 and iNOS expression scores in PA

\section{PCNA expression and PCNA-labeling index}

In NSG, the expression of PCNA was a nuclear brownish precipitate observed only in the duct cells (Fig 3A). In PA, positive expression of PCNA was observed in the ductal cells and myoepithelial cells distributed mainly at the periphery of the lesion (Fig 3B). . The mean PCNA- LI of PA was ranged between $12.4 \%$ at the center of the tumor to $15.3 \%$ at the peripheries. The staining scores of both COX2 and iNOS showed significant positive correlation with PCNA-LI $(P \leq 0.01)$ (table 3$)$.

\section{DISCUSSION}

In this study, we explored immunolocalization of iNOS, COX-2, and PCNA in PA of salivary glands of oral cavity to determine their distribution and localization pattern within the tumor and correlation. Both COX-2 and iNOS were immunolocalized in ductal cells of NSG, whereas, in PA it was observed in ductal cells surround the ducts and in cell nests as well as in myoepithelial cells of tumor tissues. These results are in accordance with the previous reports, that the expression of iNOS and COX-2 were observed in both ductal and myoepithelial cells $(21,23,28-30)$. However, in another study myoepithelial cells but not the ductal cells were suggested to be responsible for widespread expression of iNOS in $\mathrm{PA}^{(28)}$.

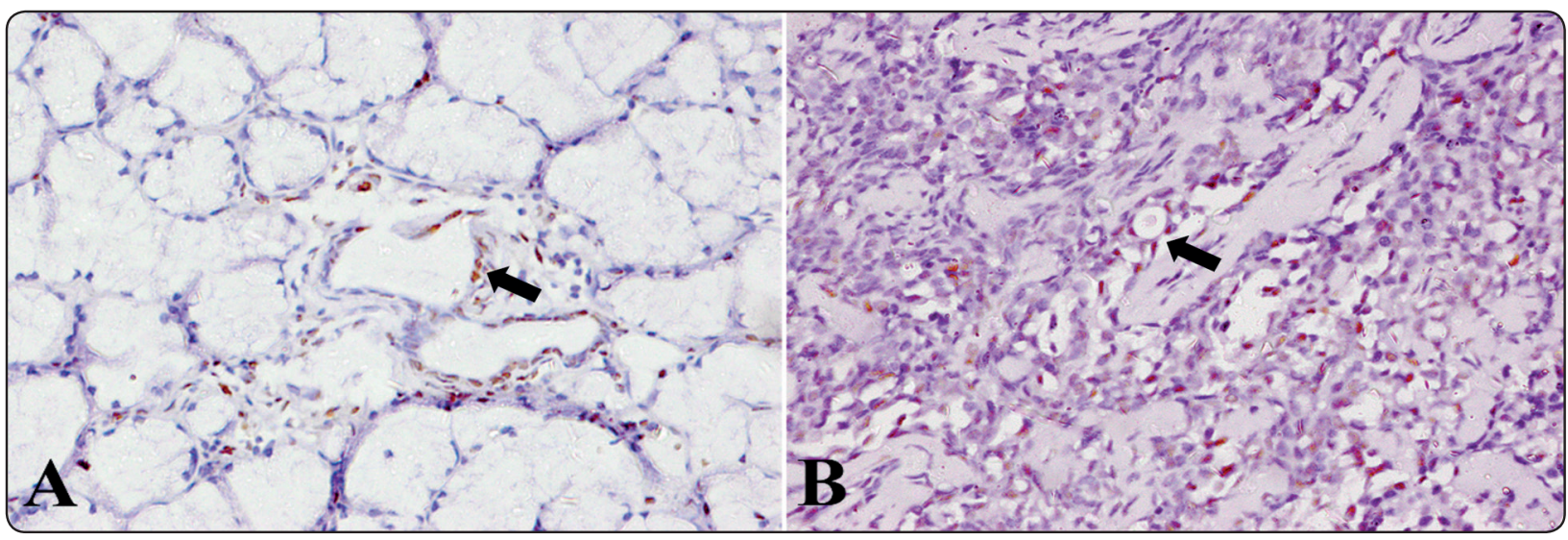

Fig. (3) Immunohistochemical staining of PCNA in A) NSG, B) PA. Hematoxylin counter stain. PCNA positive staining is observed in few cells of NSG (A) and in many tumor cells of PA (B) (arrow). X; 400 
The intensity of expressions were enhanced in PA when compared with the NSG tissues supporting the previous findings ${ }^{(21,23,30,31)}$. The most noticeable finding was the expression patterns of COX-2 and iNOS in PA, which varied according to the area of the tumor. In the center of the lesion, the expression was sporadic and the score was low to medium while in tissues near the margins of the lesion it was widely distributed, strong and upregulated and the expression score was high. Added to that the PCNA proliferative index was also higher in PA tumor tissues near the margins. These findings suggest that the tumor cells near the periphery of PA have more tumorous, aggressiveness and proliferative activity, than the tumor cells in the center of the lesion.

These findings can be explained by the previous report regarding the expression of both $\mathrm{COX}$ 2 and iNOS in other tumors of the body such as colorectal tumors ${ }^{(32)}$, in which the expression was heterogeneous and upregulated in the invasive front than center area of the tumor tissues suggesting that the periphery of the tumor is the most aggressive portion.

In our previous researches, we revealed that COX-2 expression increased in salivary gland carcinoma when compared with PA and there was a correlation between its expression and the degree of malignancy ${ }^{(23)}$. Moreover, iNOS expression was significantly increased in highgrade mucoepidermoid carcinoma when compared with low and intermediate grade mucoepidermoid carcinomas ${ }^{(24)}$ and that PCNA proliferative index was increased with the increased of malignancy ${ }^{(23)}$. Previous reports demonstrated that the increased expression of COX-2 is one of early events of malignant transformation of $\mathrm{PA}{ }^{(31)}$.

Since previous studies revealed that, there is a link between expression of COX-2 and iNOS and reported that $\mathrm{NO}$ can stimulate formation of prostaglandin through the activation of COX-2 and prostaglandins may affect iNOS expression, furthermore, in colorectal cancer COX-2 activation induce angiogenesis mediated by NO through increase production of VEGF ${ }^{33-35)}$. Therefore, iNOS could be one of early events of malignant transformation of PA and need further elucidation in recent researches.

In the current study, expression of iNOS was significantly correlated with COX-2, and that both molecules are co-localized in PA which in accordance with the previous findings and suggestion that they have an important role in progression of many epithelial tumors including salivary gland tumors ${ }^{(8-12,24,32)}$. Moreover, correlation between the expression of both investigated molecules and proliferative index of PCNA was in accordance with the previous reports ${ }^{(23,27,32)}$.

COX-2 and iNOS have been identified to have essential roles in suppression of apoptosis, proliferation, angiogenesis, invasion, and metastasis ${ }^{(1,2)}$. A sustainable NO concentrations produced by iNOS in response to pro-inflammatory agents which has antiapoptotic effects induced by TNF- $\alpha$ and Fas-ligands blocking Caspase-3 like activation ${ }^{(1)}$.

Peroxynitrites free radical is produced when endogenous NO react with superoxide anions which lead to tissue damage ${ }^{(35)}$. Furthermore, COX-2 produces prostaglandins from arachidonic acids stimulate proliferation of epithelial cells, which support the previous reports that COX-2 overexpression suppress apoptosis ${ }^{(2)}$. The previous studies reported that COX-2 inhibitors prevent the progression of several epithelial cancers of animals and human by blocking the production of VEGF, reduce tumor angiogenesis and suppress vascular endothelial cells migration ${ }^{(38,40)}$.

In conclusion, iNOS and COX-2 enzymes are localized and upregulated in PA. Their localization pattern and distribution are not the same in all areas of tumor tissues. They are more expressed, widely distributed in tissues near the tumor margins than the center area and they are positively correlated 
with each other and with the proliferative activity of the tumor cells. These findings suggest that both enzymes are colocalized, and act concomitantly during tumor progression. Further study is recommended to clarify the genetic background and relation between the expressions of both enzymes and their role in malignant transformation of PA.

\section{REFERENCES}

1. Sappayatosok K. Nitric oxide and carcinogenesis. RJAS 2012;2:45-55.

2. Dubois RN, Abramson SB, Crofford L, Gupta RA, Simon LS, Van De Putte LB, Lipsky PE. Cyclooxygenase in biology and disease. FASEB J 1998; 12: 1063-73.

3. Calvisi DF, Pinna F, Ladu S, Pellegrino R, Muroni MR, Simile MM,et al. Aberrant iNOS signaling is under genetic control in rodent liver cancer and potentially prognostic for the human disease. Carcinogenesis. 2008;29:1639-47.

4. Vane JR, Bakhle YS, Botting RM. Cyclooxygenases 1 and 2. Annu Rev Pharmacol Toxicol 1998; 38: 97-120.

5. Herschman HR: Prostaglandin synthase-2. Biochem Bioph Acta 1996; 1299: 125-140.

6. Sappayatosok K,Maneerat Y,Swasdison S, et al.Expression of pro-inflammatory protein, iNOS, VEGF and COX-2 in oral squamous cell carcinoma (OSCC), relationship with angiogenesis and their clinico-pathological correlation. Med Oral Patol Oral Cir Bucal 2009;14:319-24.

7. Wilson KT, Fu S, Ramanujam KS, et al: Increased expression of inducible nitric oxide synthase and cyclooxygenase-2 in Barrett's esophagus and associated adenocarcinomas. Cancer Res 1998; 58: 2929-34.

8. Nose F, Ichikawa T, Fujiwara M, Okayasu I. Up-regulation of cyclooxygenase- 2 expression in lymphocytic thyroiditis and thyroid tumors: significant correlation with inducible nitric oxide synthase. Am J Clin Pathol 2002;117:546-51.

9. Kim SA, Ahn SG, Kim DK, et al. Sequential expression of inducible nitric oxide synthase and cyclooxygenase-2 during DMBA-induced hamster buccal pouch carcinogenesis. In Vivo 2004;18:609-14.

10. Son HJ, Kim YH, Park DI, et al. Interaction between cyclooxygenase-2 and inducible nitric oxide synthase in gastric cancer. J Clin Gastroenterol. 2001;33:383-8.
11. Hara A and Okayasu I. Cyclooxygenase-2 and inducible nitric oxide synthase expression in human astrocytic gliomas: correlation with angiogenesis and prognostic significance. Acta Neuropathol 2004; 108: 43-8.

12. Kim KH, Kim SH, Kim SH, Back JH, Park MJ, Kim JM. Cyclooxygenase-2 and inducible nitric oxide synthase expression in thyroid neoplasms and their clinicopathological correlation. J Korean Med Sci 2006;21:1064-9.

13. Varghese SS, Sunil PM, Madhavan RN. Expression of inducible nitric oxide synthase (iNOS) in oral precancer and oral squamous cell carcinoma: an immunohistochemical study. Cancer Biomark 2010-2011;8:155-60.

14. Chen WL, Ouyang KX, Li HG et al. Expression of Inducible Nitric Oxide Synthase and Vascular Endothelial Growth Factor in Ameloblastoma. J Craniofac Surg 2009; 20:171-5.

15. Hao X, Bishop AE, Wallace M, et al: Early expression of cyclo-oxygenase-2 during sporadic colorectal carcinogenesis. J Pathol 1999; 187: 295-301.

16. Ristimaki A, Honkanen N, Jankala H, et al: Expression of cyclooxygenase- 2 in human gastric carcinoma. Cancer Res $1997 ; 57: 1276-80$

17. Yushimora R, Sano H, Masuda C, et al. Expression of Cyclooxygenase-2 in Prostate Carcinoma. Cancer 2000; 89:589-98.

18. Joki T, Heese O, Nikas DC, Bello L, Zhang J, Stine KK, et al. Expression of cyclooxygenase-2 in human gliomas and in vitro inhibition by a specific COX-2 inhibitor, NS-398. Cancer Res 2000; 60: 4926-31.

19. Denkert C, Kobel M, Berger S, et al., Expression of cyclooxygenase-2 in human malignant melanoma. Cancer Res 2001; 61: 303-308.

20. Siironen P, Ristimaki A, Nordling S, Louhimo J,Haapiainen $\mathrm{R}$, Haglund C. Expression of COX-2 is increased with age in papillary thyroid cancer. Histopathology 2004; 44: 4907.

21. Sakurai K, Urade M, Noguchi K, et al. Increased expression of cyclooxygenase-2 in human salivary gland tumors. Pathol Int 2001;51: 762-9.

22. Akrish S, Peled M, Ben-Izhak O, Nagler RM. Malignant salivary gland tumors and cyclo-oxygenase-2: a histopathological and immunohistochemical analysis with implications on histogenesis. Oral Oncol 2009; 45:1044-50. 
23. Metewaly H. Expression of COX-2 in minor salivary gland tumors and its significant relationship to tumor cell proliferation. EDJ 2012;59:

24. Metwaly H, Mohamed AE. Role of Inducible Nitric Oxide Synthase (iNOS) and Cyclooxygenase-2 (Cox-2) In Mucoepidermoid Carcinoma of Salivary Glands. EDJ 2013;59: 1963:1974.

25. van Diest PJ, Brugal G, Baak JPA. Proliferation markers in tumours: interpretation and clinical value. J Clin Pathol 1998; 51: 716-724.

26. Tubiana M, Courdi A. Cell proliferation kinetics in human solid tumors: relation to probability of metastatic dissemination and long term survival. Radiother Oncol 1989;15:1-18.

27. Russo G, Zamparelli A, Howard CM, et al. Expression of cell cycle-regulated proteins pRB2/p130, p107, E2F4, p27, and pCNA in salivary gland tumors: prognostic and diagnostic implications. Clin Cancer Res. 2005; 11: 3265-73.

28. Brennan PA, Umar T, Zaki GA, Langdon JD, Spedding A, Buckley J, Downie IP. Are myoepithelial cells responsible for the widespread expression of inducible nitric oxide synthase in pleomorphic adenoma? An immunohistochemical study. J Oral Pathol Med 2000; 29:279-83.

29. Brennan PA, Umar T, Buckley J, Zaki GA, Langdon JD, Spedding A, Peters W. Expression of nitric oxide synthase in pleomorphic adenomas of the parotid. $\mathrm{Br} \mathrm{J}$ Oral Maxillofac Surg 2000;38:338-42.

30. Masaru Y, Yoshihiro A, Michiko N, Masato S, Tohru K. An Immunohistochemical Study of the Localization of Inducible Nitric Oxide Synthase (iNOS) and Heat Shock Protein (HSP) in Pleomorphic Adenoma. Acta Histochem Cytochem 2004 ;37: 267-71.

31. Katori H1, Nozawa A, Tsukuda M. Increased expression of cyclooxygenase-2 and Ki-67 are associated with malignant transformation of pleomorphic adenoma. Auris Nasus Larynx 2007;34:79-84.
32. Cianchi F, Cuzzocrea S, Vinci MC, Messerini L, Comin CE, Navarra G, et al. Heterogeneous expression of cyclooxygenase-2 and inducible nitric oxide synthase within colorectal tumors: correlation with tumor angiogenesis. Dig Liver Dis 2010;42:20-7.

33. Perez-Sala D, Lamas S. Regulation of cyclooxygenase-2 expression by nitric oxide in cells. Antioxid Redox Signal 2001; 3: 231-48. 27.

34. Kobayashi O, Miwa H, Watanabe S, Tsujii M, Dubois RN, Sato N. Cyclooxygenase-2 downregulates inducible nitric oxide synthase in rat intestinal epithelial cells. Am J Physiol Gastrointest Liver Physiol 2001; 281: 688-96.

35. Cianchi F, Cortesini C, Fantappiè O, Messerini L, Sardi I, Lasagna $\mathrm{N}$, et al. Cyclooxygenase-2 activation mediates the proangiogenic effect of nitric oxide in colorectal cancer. Clin Cancer Res 2004 ;10:2694-704.

36. Reddy BS, Maruyama H, Kelloff G. Dose-related inhibition of colon carcinogenesis by dietary piroxicam, a non-steroidal anti-inflammatory drug during different stages of rat colon tumor development. Cancer Res 1987; 47: 5340-6.

37. Giovanucci E, Egan KM, Hunter DJ. Aspirin and the risk of colorectal cancer in women. N Engl J Med 1995; 333: 609-14.

38. DuBois RN, Awad J, Morrow J, Roberts LJ, Bishop II PR. Regulation of eicosanoid production and mitogenesis in rat intestinal epithelial cells by transforming growth factoralpha and phorbol ester. J Clin Invest 1994; 93: 493-8.

39. Sivani M,Joel BE. Carcinogenesis and cyclooxygenase: the potential role of COX-2 inhibition in upper aerodigestive tract. Cancer 2003;39: 537-546

40. Xin X, Majumder M, Girish VG, Mohindra V, Maruyama T, Lala KP. Targeting COX-2 and EP4 to control tumor growth, angiogenesis, lymphangiogenesis and metastasis to the lungs and lymph nodes in a breast cancer model. Lab Invest 2012; 92: 1115-28. 